\title{
Roles, rituals and emotional regulation of rugby players at different competitive levels
}

\author{
Petronella A Hough, BOT (UFS), MOT (UFS) https://orcid.org/0000-000 I-993 I-6360 \\ Lecturer, Department of Occupational Therapy, School of Allied Health Professions, Faculty of Health Sciences, University of the \\ Free State, Bloemfontein
}

Mariette Nel, BA (UFS), BA Hons (UFS), M Med Sc in Biostatistics https://orcid.org/0000-0002-3889-0438 Lecturer, Department of Biostatistics, School of Medical Sciences, Faculty of Health Sciences, University of the Free State, Bloemfontein

**Trohandi de Klerk, BOT (UFS) MECI (UP) https://orcid.org/0000-0003-4499-3924

North West Department of Basic Education's unit for Learners with Severe to Profound Intellectual Disabilities (LSPID)

**Janine Human, BOT (UFS) https://orcid.org/0000-0003-2339-28I2

Private Practice, Workwell Certified Practitioner

***Tler Voight, BOT (UFS) https://orcid.org/0000-000 I-570 I- I 884

Band 6 Rotational Occupational Therapist, Queens Hospital. Barking, Havering and Redbridge University Hospitals, London

**Jana van der Neut, BOT(UFS) https://orcid.org/0000-0002-6328-7999

Blocks4Growth Occupational Therapist at The Learning Initiative (TLI)

**Fourth Year Occupational Therapy Students at the time that the study was conducted.

Globally, people engage in the game of rugby as spectators, players and organisations on many different competitive levels for the purpose of leisure, work and play. It is performed on both amateur and professional levels and engaged in by male and female players ranging from pre-school to adults. The purpose of the study was to describe and compare the roles, rituals and emotional regulation, on and off the field, of male rugby players on three different competitive levels in the Free State, South Africa. A cross-sectional study design was used amongst rugby players $(n=45)$; I team per competitive level (3 levels). The results of the study showed significant differences with regards to roles that rugby players on the different competitive levels assume and the importance which they ascribe to each role. Variations exist in the rituals that the rugby players on the different competitive levels perform before and during a game of rugby. The degree to which situations are experienced as stressful differs across the three competitive levels. Across these levels, the use of positive verbal and non-verbal expression is used more than negative expression. Across all three levels rugby players use emotional suppression more than situational reappraisal as an emotional regulation strategy. Additional factors and the comparison thereof on different competitive levels should be investigated in future studies.

Key words: Roles, rituals, emotional regulation, occupation, rugby

\section{INTRODUCTION}

Occupational therapy is the unique art and science of promoting an individual's capacity to participate and engage, to their full potential, in personally meaningful and valued occupations ${ }^{1,2,3}$. An occupation is much more than a chosen career. It encompasses all activities of daily life that foster health and well-being in, amongst others, instrumental activities of daily living, play, leisure, work and social participation ${ }^{2}$. Due to the increased focus on health and function in community settings, it is important for occupational therapists to investigate occupations and develop approaches that are unique in community health, and health promotion settings ${ }^{2}$. Globally, rugby is a popular and growing sport that is participated and engaged in by male and female players of different ages as both a leisure activity and professional occupation that is participated in on various competitive levels $\mathbf{s}^{4,5}$. Taking this into account, participation and engagement in the occupation of rugby thus has the potential to influence the players' health and well-being ${ }^{2}$. Steinwender \& Leclair $^{6}$ state that health flourishes when a person's occupation gives meaning and purpose to their life $\mathrm{e}^{1,2,3}$. For players, rugby is considered such an occupation. Add the element of competition and rugby becomes an occupation that places various demands on participants. The meaningful roles that competitive rugby players assume, the rituals they participate in and the emotional regulation strategies they opt to use due to these demands, may influence their well-being.

Although research on individual roles of athletes and how these influence their health and well-being is limited ${ }^{7,8,9,10}$, it is a known fact that internalised roles provide a framework for occupational engagement, which contributes positively to participation and well-being ${ }^{11,12}$. However, the multiple and possibly varying roles that rugby players on different competitive levels assume on and off the field could lead to role conflict and role prioritisation, which in turn may negatively influence engagement, participation and well-being over time and throughout life stages ${ }^{13,14,15,16}$. In order 
to better understand the impact of rugby as an occupation on the health and wellbeing of competitive rugby players, this study firstly investigated the roles that rugby players assume; not only as a rugby player, but also within their family and social context of occupational engagement.

In addition to understanding the roles rugby players assume, the rituals that they value also need to be taken into account ${ }^{17}$. These symbolic actions serve as a coping mechanism for the varying intensities of pressure and anxiety associated with participating in rugby on different competitive levels ${ }^{18,19}$. The current study therefore secondly investigated which rituals were valued by rugby players on different competitive levels.

As is the case with roles and rituals, emotional regulation has the potential to influence competitive rugby players' occupational participation and engagement, and thus their health and well-being. It is known that emotional regulation significantly impacts mental and physical health ${ }^{20,21}$, social functioning ${ }^{22}$, interpersonal relationships $^{23}$ and work performance ${ }^{24}$. Gross and Thompson ${ }^{20}$ describe emotional regulation as the automatic or deliberate use of strategies to initiate, maintain, modify or display emotions. When looking at rugby as an occupation, poor emotional regulation could lead to injuries to themselves and other players; disruptions to the flow of the game ${ }^{25}$; disciplinary action and could ultimately cost the player their rugby career. Various authors ${ }^{20,26,27}$ agree that there are many strategies which athletes utilise to regulate their emotions. For the purpose of the current study the strategies of emotional suppression (hereafter referred to as suppression) and situational reappraisal (hereafter referred to as reappraisal) ${ }^{20}$ were investigated among rugby players on different completive levels to better understand the effect that occupational participation and engagement in rugby has on players' overall health and well-being.

Thus, the aim of the current study was to describe and compare the roles that rugby players assume, on and off the field, the rituals that they perform and how they regulate their emotions as pertaining to different competitive levels, namely: residence league-, club- and provincial levels of rugby.

\section{METHODOLOGY}

A cross-sectional study was conducted after obtaining ethical clearance from the Research Ethics Committee of the Faculty Health Sciences at the University of the Free State (STUD NR: 10/20I5) as well as relevant authorities, and informed written consent from the participants.

A four-part self-administered questionnaire was designed to collect data on biographical factors, roles, rituals and emotional regulation of the participants. To ensure validity and reliability of the current study, questions on roles and rituals were based on a thorough literature review. The following subsections were identified and included in the questionnaire for the roles and rituals section: I) Roles: family and social roles, roles within the rugby context and recreational roles; 2) Rituals: type of rituals performed, with whom, where and why. For both these sections participants ranked their roles and rituals from the most (score I) to least important (score $2,3,4,5$, etc.). For the first subsection of the emotional regulation section the players had to rank stressful situations from the most (score I) to least stressful (score 2,3,4,5, etc.). For the second subsection a validated questionnaire, namely the Emotional Regulation Questionnaire (ERQ) ${ }^{28}$ was used. The scale uses a 7-point Likert scale for answers to questions on suppression and reappraisal. The researchers adapted the content of the questions to ensure relevance to the current study, with regards to the emotional regulation of rugby players on and off of the field.

Prior to data collection a pilot study was conducted. There were no contextual changes made to the questionnaire and these results were excluded from the analysis.

A convenience sample of I 5 rugby players from a team on each competitive level, namely Residence Abraham Fischer (residence league), the Shimlas (university league) and the Cheetahs (provincial level) were included in the data collection $(n=45)$. The study sample consisted of male rugby players older than 18 years engaging in rugby during the time of data collection. Each playing position from every team was represented.

The questionnaires were completed by the study participants during pre-arranged group contact sessions. The researchers were present during completion of the questionnaires to respond to questions.

The coding was done by the researchers, followed by data analysis done by the Department of Biostatistics at the UFS. Descriptive statistics, namely frequencies and percentages for categorical data and medians and percentiles for numerical data were calculated per competitive level. The competitive levels were compared by means of $95 \%$ confidence intervals $(\mathrm{Cl})$ for percentage and median differences, or the Kruskal-Wallis test when sample size was small.

\section{RESULTS}

The median age for residence level was 21 years (range 19 to 23 ), for club level 22 years (range 20 to 24 years) and for provincial level 24 years (range 22 to 31 ). A significant difference in age existed between club level and provincial level as indicated by the $95 \%$ confidence interval $(\mathrm{Cl}=[-5 ;-\mathrm{I}])$ as well as between provincial and residence level $([2 ; 7])$.

The median years that the rugby players had played rugby for their current team was as follows: 2 years for club level (range I to 5); 4 years for provincial level (range I to II) and 2 years for residence level (range I to 5 ). With regard to marital status and dependants, club level and residence level consisted of 15 unmarried rugby players in each team with no children. In provincial level 4 of the 15 rugby players were married and 3 of the 15 players had children.

As seen in Table I below, the three roles that rugby players assumed the most across all three teams differed. These were, for club level: rugby player, other occupations (student and/or

Table I: Roles rugby players on three different competitive levels assume and the ranking of importance of each role

\begin{tabular}{|c|c|c|c|c|c|c|}
\hline \multirow{2}{*}{ Roles } & \multicolumn{2}{|c|}{ Club Level $(n=15)$} & \multicolumn{2}{|c|}{ Provincial Level $(n=15)$} & \multicolumn{2}{|c|}{ Residence Level $(n=15)$} \\
\hline & Frequency (\%) & Median (Range) & Frequency (\%) & Median (Range) & Frequency (\%) & Median (Range) \\
\hline Rugby Player & $15(100)$ & $40 *(12.5-100)$ & $15(100)$ & 57. $*(25-80)$ & $15(100)$ & $87.5 *(12.5-100)$ \\
\hline Other occupations & $15(100)$ & $40 *(12.5-80)$ & $8(53)$ & $100 *(50-100)$ & $15(100)$ & $68.8 *(12.5-100)$ \\
\hline Father & I (6.7) & $80 *(25-87.5)$ & $3(20)$ & $33.3 *(16.7-50)$ & $2(13.3)$ & $33.3(12.5-100)$ \\
\hline Partner ${ }^{\circ}$ & $\mathbf{0}(0)$ & $75(40-100)$ & $6(40)$ & $50(14.3-100)$ & I (6.7) & $50(25-100)$ \\
\hline Son & $14(93.3)$ & $37.5(20-80)$ & I I (73.3) & $41.5(20-75)$ & $12(80)$ & $36.7(12.5-75)$ \\
\hline Grandson & $12(80)$ & $68.8 *(37.5-100)$ & $5(33.3)$ & $84.5 *(40-100)$ & $4(26.7)$ & $71.3(37.5-100)$ \\
\hline Friend & $13(86.7)$ & $62.5(12.5-100)$ & I I (73.3) & $80 *(20-100)$ & $15(100)$ & $50 *(25-75)$ \\
\hline
\end{tabular}

${ }^{\circ}$ Member of a married couple or of an established unmarried couple (Oxford Dictionaries 2015)

* Significant Difference between levels 
work) and son; for provincial level: rugby player: friend and son; for residence level: rugby player, other occupations (student and/ or work) and friend. A significant difference was identified with regards to other occupations between club and provincial level (95\% Cl for the percentage difference [19.8\%; 74.2\%]) as well as between provincial and residence level ([-64.0\%; -5.0\%]). Another significant difference was found for the role of a grandson between club- and provincial level ([5.0\%; 64.0\%]).

The importance of the assumed roles for the rugby players were compared across the teams. A lower value indicates that the rugby players ranked the role as more important and a higher value, as less important. Significant differences were found in: the importance of the role of a rugby player when comparing club- and provincial level with residence level $(p=0.0 \mathrm{l})$; the importance of the role assumed in other occupations (student/work) between club- and provincial level $(p=0.003)$ and between provincial- and residence level $(p=0.02)$; the importance of the role of a father between club- and provincial level $(p=0.05)$; and lastly the importance of the role of a friend between provincial- and residence level $(p=0.0 \mathrm{I})$.

When referring to participation in additional occupations to rugby (see Table II below), there was a significant difference in the number of players that were students between club- and

Table II: Additional occupations that rugby players participate and engage in on three different competitive levels

\begin{tabular}{|c|c|c|c|}
\hline \multirow[t]{2}{*}{ Occupations } & $\begin{array}{l}\text { Club Level } \\
(n=15)\end{array}$ & $\begin{array}{c}\text { Provincial } \\
\text { Level }(n=15)\end{array}$ & $\begin{array}{c}\text { Residence } \\
\text { Level }(n=15)\end{array}$ \\
\hline & $\begin{array}{l}\text { Frequency } \\
\text { (\%) }\end{array}$ & $\begin{array}{l}\text { Frequency } \\
(\%)\end{array}$ & $\begin{array}{c}\text { Frequency } \\
(\%)\end{array}$ \\
\hline Student & $15 *(100)$ & 6* (40) & $15 *(100)$ \\
\hline Work & $3(20)$ & $4(26.7)$ & $4(26.7)$ \\
\hline $\begin{array}{l}\text { Student and } \\
\text { Work }\end{array}$ & $3(20)$ & I (6.7) & $4(26.7)$ \\
\hline
\end{tabular}

provincial level ([28.3\%; $80.2 \%])$ as well as between provincialand residence level ([-80.2\%; -28.3\%]).

As seen in Table III below, significant differences were found between the different teams when comparing the following rituals performed before a game of rugby: listening to music between provincial- and residence level ([0.5\%; 58.5\%]), visualisation between club- and residence level ([0.5\%; 58.5\%]) and singing of the anthem between club- and provincial level $([12.2 \% ; 69.0 \%])$ and between club- and residence level ([19.8\%; 74.2\%]).

Rugby players at club level tended to make more use of the ritual of visualisation during a game of rugby when compared to rugby players on a provincial- ([- $10.5 \% ; 46.8 \%])$ and residence level ([-0.5\%; $58.8 \%])$, although not statistically significant.

Table IV on page 54 indicates the number of rugby players who identified the respective situations as being stressful and how these situations are ranked from being the most stressful to least stressful. Majority of rugby players across all three teams ranked injury, mental errors and physical errors made by oneself as stressful. These results further revealed significant differences for the following situations: club level experiences physical errors made by oneself as more stressful than provincial level $(p=0.05)$, provincial level experiences an injury as more stressful than club level $(p=0.03)$ and provincial level experiences bad weather conditions as more stressful than residence level $(p=0.04)$.

Table $V$ on page 54 indicates that players at residence level tended to make use of encouragement more than club- ([-37.9\%; $9.2 \%]$ ) and provincial level ([-37.9\%; 9.2\%]). Threatening had a tendency to be used more by club level as opposed to residence- ([-10.5\%; 46.7\%]) and provincial level ([- $10.5 \% ; 46.7 \%])$. Residence level tended to swear less than club- ([-I.7\%; 58.9\%]) and provincial level ([-8.1\%; 53.8\%]). Name calling tended to be used the least by provincial level when compared to club- ([-2.8\%; $52.2 \%)]$ and residence level ([-39.1\%; I3.2\%]). With regards to verbal expressions, club- and provincial level significantly differed ([2.6\%; 58.2\%]) when referring to teasing.

A significant difference existed between club- and provincial level ([8.2\%; 63.9\%]), where club level made use of body move-

Table III: Rituals that rugby players on three different competitive levels performed before and during a game of rugby

\begin{tabular}{|c|c|c|c|}
\hline \multirow{2}{*}{ Rituals } & Club Level $(n=15)$ & Provincial Level $(n=15)$ & Residence Level $(n=15)$ \\
\hline & Frequency (\%) & Frequency (\%) & Frequency (\%) \\
\hline \multicolumn{4}{|l|}{ Rituals performed before a game of rugby } \\
\hline Listening to Music & $12(80)$ & $13 *(86.7)$ & $8 *(53.3)$ \\
\hline Positive Self-speech & $8(53.3)$ & $8(40)$ & $8(53.3)$ \\
\hline Visualisation & $13 *(86.7)$ & $10 *(66.7)$ & $8(53.3)$ \\
\hline Prayer & $12(80)$ & $14(93.3)$ & $13(86.7)$ \\
\hline Body Warm- Up & I I (73.3) & $10(66.7)$ & $9(60)$ \\
\hline Kissing of a Symbolic Object & $\mathbf{0}(0)$ & $\mathbf{I}(6.7)$ & $\mathbf{0}(0)$ \\
\hline Singing & $2(13.3)$ & $2(13.3)$ & $2(13.3)$ \\
\hline Anthem & 9* $(60)$ & $2 *(13.3)$ & I* $(6.7)$ \\
\hline \multicolumn{4}{|l|}{ Rituals performed during a game of rugby } \\
\hline Positive Self Speech & $10(66.7)$ & $10(66.7)$ & $8(53.3)$ \\
\hline Kissing of a Symbolic Object & $\mathbf{0}(0)$ & $\mathbf{O}(0)$ & $\mathbf{0}(0)$ \\
\hline Prayer & $9(60)$ & $9(60)$ & I I (73.3) \\
\hline Counting & $3(20)$ & I (6.7) & I (6.7) \\
\hline Visualisation & $10 *(66.7)$ & $6 *(40)$ & $5(33.3)$ \\
\hline Motivating a team mate and receiving motivation & $10(66.7)$ & I I (73.3) & $10(66.7)$ \\
\hline Stretching & $7(46.7)$ & $8(53.3)$ & $7(46.7)$ \\
\hline
\end{tabular}


ments or gestures more than provincial level. Furthermore, club level had a tendency to do so more than residence level ([-8.0\%; $54.9 \%])$.

For the Emotional Regulation Questionnaire (ERQ) ${ }^{28}$ (see Table VI on page 55) a Likert scale of 7 (I=agree, $7=$ disagree) was used where the rugby players agreed or disagreed with six reappraisals and four suppression statements, for both on the rugby field and within a social setting. A lower median means that the rugby players agreed more and a higher median that they disagreed more with the statement in the questionnaire.

For suppression in a social setting a statistically significant difference was found $(\mathrm{Cl}$ : $[-1.5 ;-0.25])$ between club- and residence

Table IV: Stressful situations that rugby players on three different competitive levels experience during a game of rugby and the degree to which the situations are perceived as being stressful

\begin{tabular}{|c|c|c|c|c|c|c|}
\hline \multirow{2}{*}{ Stressful Situations } & \multicolumn{2}{|c|}{ Club Level $(n=15)$} & \multicolumn{2}{|c|}{ Provincial Level $(n=15)$} & \multicolumn{2}{|c|}{ Residence Level $(n=15)$} \\
\hline & Frequency (\%) & Median (range) & Frequency (\%) & Median (range) & Frequency (\%) & Median (range) \\
\hline $\begin{array}{l}\text { Physical errors made by } \\
\text { oneself }\end{array}$ & $15(100)$ & $10 *(7.1-42.9)$ & $13(86.7)$ & $16.7 *(7.1-100)$ & $15(100)$ & I4.3 (7.I-75) \\
\hline $\begin{array}{l}\text { Physical errors made by } \\
\text { a team member }\end{array}$ & $14(93.3)$ & 48.I (7.7-92.9) & I I (73.3) & $61.5(23.1-100)$ & I I (73.3) & $42.9(14.3-100)$ \\
\hline $\begin{array}{l}\text { Mental errors made by } \\
\text { oneself }\end{array}$ & $15(100)$ & $23.1(15.4-100)$ & $14(93.3)$ & $25(7.7-100)$ & $13(86.7)$ & $23.1(7.7-6 \mid .5)$ \\
\hline An injury & $15(100)$ & $57.1 *(23.1-100)$ & $13(86.7)$ & $30.8 *(8.3-100)$ & $15(100)$ & $30.8(7.1-100)$ \\
\hline $\begin{array}{l}\text { Injury of a key team } \\
\text { member }\end{array}$ & $13(86.7)$ & $69.2(30-100)$ & $10(66.7)$ & $59.9(38.5-100)$ & $12(80)$ & $40.7(21.4-92.9)$ \\
\hline Criticism from the coach & $12(80)$ & $33.3(7.1-85.7)$ & $10(66.7)$ & $50(7.7-87.5)$ & $13(86.7)$ & $38.5(7.7-85.7)$ \\
\hline $\begin{array}{l}\text { An opponent playing } \\
\text { well }\end{array}$ & $12(80)$ & $61.5(30.8-92.3)$ & $9(60)$ & $84.6(15.4-92.3)$ & I I (73.3) & $69.2(28.6-92.3)$ \\
\hline An opponent cheating & I I (73.3) & $76.9(38.5-100)$ & $10(66.7)$ & $74.2(30.8-100)$ & I I (73.3) & $64.3(38.5-92.3)$ \\
\hline $\begin{array}{l}\text { Receiving a wrong call } \\
\text { from the official }\end{array}$ & $13(86.7)$ & $53.8(30.8-100)$ & I I (73.3) & $46.2(7.7-100)$ & $12(80)$ & $51.9(23.1-78.6)$ \\
\hline Bad weather & $13(86.7)$ & $64.3(15.4-92.3)$ & $10(66.7)$ & $61.5 *(42.9-84.6)$ & $12(80)$ & 77.8* (35.7-100) \\
\hline $\begin{array}{l}\text { Poor turnout or lack of } \\
\text { support from the crowd }\end{array}$ & II (73.3) & $84.6(42.9-100)$ & $8(53.3)$ & $81.3(38.5-100)$ & II (73.3) & $85.7(53.8-100)$ \\
\hline Confusion by drills & $14(93.3)$ & $55.5(28.6-100)$ & $12(80)$ & $60.4(7.1-100)$ & $12(80)$ & $57.7(7.1-92.9)$ \\
\hline $\begin{array}{l}\text { Miscommunication } \\
\text { between team members } \\
\text { on the field }\end{array}$ & $15(100)$ & $42.9(7.1-100)$ & $12(80)$ & $68(14.3-100)$ & I I (73.3) & $76.9(30.8-100)$ \\
\hline
\end{tabular}

Table V: Verbal and non-verbal expressions used by rugby players on three different competitive levels use during a game of rugby directed towards other players, the coach or referee

\begin{tabular}{|c|c|c|c|}
\hline \multirow{2}{*}{ Expressions } & Club Level $(n=15)$ & Provincial Level $(n=15)$ & Residence Level $(n=15)$ \\
\hline & Frequency (\%) & Frequency (\%) & Frequency (\%) \\
\hline \multicolumn{4}{|l|}{ Verbal expressions } \\
\hline Encouraging & $13(86.7)$ & $13(86.7)$ & $15(100)$ \\
\hline Congratulating & $13(86.7)$ & $13(86.7)$ & $13(86.7)$ \\
\hline Telling someone how you feel & $3(20)$ & $7(46.7)$ & $5(33.3)$ \\
\hline Teasing & 6* (40) & I* (6.7) & $5(33.3)$ \\
\hline Threatening & $5(33.3)$ & $2(13.3)$ & $2(13.3)$ \\
\hline Swearing & I I (73.3) & $10(66.7)$ & $7(46.7)$ \\
\hline Shouting & $7(46.7)$ & $8(53.3)$ & $7(46.7)$ \\
\hline Name calling & $5(33.3)$ & $\mathbf{I}(6.7)$ & $3(20)$ \\
\hline \multicolumn{4}{|l|}{ Non-verbal expressions } \\
\hline Touch & $14(93.3)$ & I I (73.3) & $13(86.7)$ \\
\hline Facial expressions & $5(33.3)$ & $4(26.7)$ & $2(13.3)$ \\
\hline Body movements or gestures & $14 *(93.3)$ & 8* (53.3) & I I (73.3) \\
\hline Physical aggression & $5(33.3)$ & $4(26.7)$ & $4(26.7)$ \\
\hline Ignoring & $3(20)$ & $4(26.7)$ & $3(20)$ \\
\hline
\end{tabular}


Table VI: Emotional regulation: reappraisal and suppression used by rugby players on three competitive levels during a game of rugby and in social setting

\begin{tabular}{|c|c|c|c|}
\hline \multirow{2}{*}{$\begin{array}{l}\text { Emotional Regulation } \\
\text { Strategies }\end{array}$} & Club Level $(n=15)$ & Provincial Level $(n=15)$ & Residence Level $(n=15)$ \\
\hline & Median (range) & Median (range) & Median (range) \\
\hline Reappraisal - Rugby & $5.0(2-6.7)$ & $5.2(3.9-7.0)$ & $5.3(3.3-6.5)$ \\
\hline Reappraisal - Social & $5.3(3.8-6.8)$ & $5.7(4.3-7.0)$ & $5.0(3.8-6.5)$ \\
\hline Suppression - Rugby & $3.5(1.5-4.8)$ & $3.3(2.3-5.5)$ & $3.8(1.8-5.5)$ \\
\hline Suppression - Social & $2.3 *(1.3-4.0)$ & $2.8(1.0-6.3)$ & $3.5 *(2.3-5.3)$ \\
\hline
\end{tabular}

level. It was noted that in social settings as well as on the rugby field, all three teams were inclined to make use of suppression rather than reappraisal.

\section{DISCUSSION}

Results from this study reflect how roles, rituals and emotional regulation strategies of rugby players on three different competitive levels vary and provides insight into how these aspects could influence competitive rugby players' health and well-being over time and at various life stages.

Literature indicates that rugby players take on certain roles within a team, at home and in social settings ${ }^{29}$. The current study found this to be true for the study population. Stubley ${ }^{30}$ and Cinamom $^{31}$ state that participating in accumulative roles, as most players on all three competitive levels do, could potentially lead to role conflicts. This is concerning as McGregor ${ }^{32}$ found that role conflict, and the consequent role prioritisation that follows, leads to a decrease in family, social and occupational engagement and participation, as well as overall health and well-being.

Provincial level rugby players were the only individuals to receive remuneration for playing competitive rugby in this study and they were the group most likely to be fathers. These players are thus likely to be juggling conflicting roles ${ }^{33}$. The remuneration received from playing rugby allows them to contribute financially to their families. However, the time and energy demands of playing rugby on this level could be conflicting with family functioning and responsibilities. This role conflict places provincial level rugby players at risk of occupational dysfunction and could thus influence their overall health and well-being in a negative manner ${ }^{13,14,30,31,32}$.

The current study found that club level rugby players valued the role of a rugby player more than the other levels. This is possibly because they feel that they have a vital role within the rugby team and are socially well-known. This could be ascribed to the fact that the club level team, the Shimlas, won the 2015 Varsity Cup which took place prior to data collection. According to Karageorghis and Terry $^{34}$, winning increases the feeling of competence. The pressure of associating winning rugby matches with being competent ${ }^{35}$ and reputable ${ }^{34}$ may lead to role conflict between being a rugby player and other occupations such as work or being a student.

For both club- and residence level players, role conflict between being a rugby player and other occupations (such as work or being a student), could be highly problematic if it results in an inability to function optimally in either role. This is because as opposed to provincial level, club- and residence level are obliged by university policy to be registered students at the University ${ }^{35}$. The inability to fully participate in one or both roles could therefore cause these players to feel less competent ${ }^{35}$ or reputable ${ }^{34}$ and cost them their academic career ${ }^{35}$ and/or future earning potential ${ }^{34}$. Dysfunctional occupational participation and engagement in the occupation of rugby could thus have serious implications for these players' immediate and future health and well-being ${ }^{2}$.

Notably, residence league players value the role of friend more than the other two teams. This could be because residence league players perform numerous activities of daily living, as well as social and academic activities in an environment that requires them to navigate social relationships on a daily basis. The researchers hypothesise that the unique social context of a South African university residence might explain why the rugby players on this level value the role of friend more. It is also possible that these players, on the lowest level of competition, use rugby as an enabling occupation ${ }^{2}$. Here rugby may be used as a means to facilitate friendships and social interaction. In this case, role conflict between being a rugby player and being a student could directly influence these players' ability to fulfil the valued role of being a friend and so negatively affect their health and well-being $2,3,4$.

It is clear that the roles which rugby players have internalised, and the value that they ascribe to them, differ for various competitive levels. Roles are dynamic and as such, are bound to vary over time and throughout life stages ${ }^{37}$. Christiansen, Baum and Bass-Haugen $^{36}$ state that assumed roles change throughout life as role importance is ascribed differently. It is thus important to take the age, life stage and individual role participation of the person participating in the occupation of rugby into consideration when determining potential role conflicts.

Roles and rituals are interlinked and influence one another as they shape the identity of individuals and reinforce their values and beliefs ${ }^{37}$. Rituals serve as a means to achieve an emotional state and a level of confidence before and during the execution of a $\operatorname{task}^{38}$. Literature links the use of a ritual such as listening to music before a rugby game to increased pre-game activation, positive emotions, motivation, performance levels and the experience of flow $^{39,40}$. Experiencing flow has specifically been found to increase awareness and concentration, as well as decrease anxiety, which in turn improves occupational engagement, participation and overall performance ${ }^{41}$. A study conducted by Hall, Rodgers, and Barr ${ }^{42}$ further revealed that athletes on higher competitive levels are more likely to make use of visualisation as ritual.

The above finding could be an indicator of why provincial level and club level players respectively reported using listening to music and visualisation significantly more than residence league players did. Taking the literature into account $38,39,40,41,42$, it is arguable that within the occupation of rugby, higher levels of competition place an increased demand on the player to be able to fully participate and engage in the game of rugby. Furthermore, this increased demand on occupational performance necessitates the use of rituals in order to build up a suitable emotional state before a game of rugby, as well as to sustain or improve occupational engagement, participation and overall performance during a game of rugby.

It is however, important to distinguish between a ritual and a routine. This became evident when only nine out of fifteen club level players indicated that they perceived singing the national anthem before a game of rugby as a ritual. This, despite the fact that since 1995 the sponsors of the Varsity Cup, in which club level participates, require that all rugby teams that partake in the competition sing the national anthem ${ }^{43}$. The researchers postulate that the remaining 6 players regard singing of the national anthem merely as a pregame routine, as opposed to a ritual with symbolic meaning. Without meaning, mere routines will not sufficiently facilitate the needed emotional state and a level of confidence rugby players need on competitive levels ${ }^{39}$. 
This is important as there are many potentially stressful situations that could influence rugby players' participation and engagement in a game of rugby. The majority of players across all three competitive levels perceived injury, mental errors made by oneself and physical errors made by oneself as being stressful. These findings directly correlate with literature as being the three most stressful situations for rugby players ${ }^{44}$. If players are unable to cope with stressors associated with the occupation of rugby on a competitive level, their ability to participate and engage in this occupation to their full potential, becomes impaired and places their health and well-being at risk due to occupational dysfunction ${ }^{2,14}$.

One might expect these stressors to result in spontaneous or deliberate aggressive shows of emotional expression ${ }^{44}$ on the field. However, the current study found that all three teams used positive verbal and non-verbal emotional expressions more often than negative ones. Of the many emotions, anger is frequently expressed as aggressive behaviour (particularly in a contact sport such as rugby) among players, coaches and spectators $\mathrm{s}^{45-47}$. However, a study done in 2014 by Dublihlela \& Chinomona ${ }^{48}$ showed that, even though South African athletes experience hostility, anger, verbal aggressive behaviours and physical aggression similarly to Western populations, they have a general tendency to disapprove of aggressive behaviour.

The results of the adapted $E R Q^{28}$ sheds some light on this phenomenon. These results indicated that all three teams tended to use suppression as an emotional regulation strategy rather than reappraisal, both while participating in the occupation of rugby and in other social settings. Although emotional suppression might be an effective emotional regulation strategy in preventing unwarranted aggression, literature shows it to be a less healthy option than emotional reappraisa ${ }^{49}$. Using suppression as an emotional regulation strategy can affect these players' mental and physical health, social functioning, interpersonal relationships, work performance and general well-being in a negative manner ${ }^{50,51}$. This suppressive trend compromises competitive rugby players' health and wellbeing and places them at risk for occupational dysfunction in more occupations than just that of rugby.

\section{CONCLUSION}

The current study found the occupation of rugby to be significantly meaningful to those players who participated in the study. It also highlights how participating in this occupation could potentially influence player's engagement and participation in other roles. Evidence from the study emphasises differences and similarities between roles, rituals and emotional regulation of rugby players on different competitive levels. The study also found that within the context and environment of rugby players on different competitive levels roles, rituals and emotional regulation can affect engagement, participation and well-being.

In particular, the results showed that the roles rugby players assume and the value which they ascribe to each role varies significantly on different competitive levels. Although there are similarities with regards to rituals that rugby players perform before and during a game of rugby, there are significant differences between different competitive levels. These significant differences are due to various contextual and personal factors. Rugby players on all three competitive levels perceived the same situations within rugby as stressful. However, it is apparent that the degree to which these situations are experienced as being stressful differ significantly across the three competitive levels. Across all three levels, the use of positive verbal and non-verbal expression was used more than negative verbal and non-verbal expression. Furthermore, across all three competitive levels, suppression was consistently used more than reappraisal during a game of rugby and in social settings, potentially compromising rugby players' health and well-being.

People participate and engage in rugby on many different levels for the purpose of leisure, work and play. Occupational therapists are ideally suited to promote occupational participation and engagement in valued and meaningful occupations for the purpose of fostering health and well-being. 2,4,5,6 This study adds evidence to the knowledge base of community occupation regarding the potentially significant impact of roles, rituals and emotional regulation on participation and engagement in the occupation of competitive rugby and the impact thereof on player's health and well-being.

Occupational therapists, have a role to play in promoting healthy occupational engagement and participation, as well as preventing potential occupational dysfunction due to role conflict, insufficient coping strategies and a potentially harmful approach to emotional regulation amongst competitive rugby players.

\section{RECOMMENDATIONS}

It is recommended that follow-up studies be done to investigate (i) role conflict and the impact on occupational engagement, (ii) team rituals and their influence on the team cohesion and performance, and (iii) why certain situations are perceived to be more stressful on different competitive levels.

It is further recommended that performance patterns and client factors, as described in the Occupational Therapy Practice Framework ${ }^{37}$, be investigated on different levels of competition. This would allow a better understanding of the occupational performance demands that participation and engagement in rugby places on the players.

\section{ACKNOWLEDGEMENTS}

The authors wish to thank all the participants and rugby authorities who participated in the study. We would also like to express our gratitude to Thea Botma for her valuable contribution to the research project.

\section{REFERENCES}

I. Townsend EA and Polatajko HJ. Enabling occupation II: Advancing an occupational therapy vision for health, well-being \& justice through occupation (2 ${ }^{\text {nd }}$ ed.) Ottawa: CAOT 2013: 380.

2. New York University: Department of Occupational Therapy. A Definition of Occupational Therapy. 2015. http://steinhardt.nyu. edu/ot/definition. (2 June 20I5).

3. Canadian Association of Occupational Therapists. Occupational therapy - Definition. 2015. http://www.caot.ca/default. asp?pageid = I344. (3 June 2015).

4. Corrado DD, Murgia M and Freda A. Attentional focus and mental skills in senior and junior professional rugby union players. Sport Sciences for Health. 2014; 10(2): 79-83. https://doi.org/10.1007/s I | 332-014-0177-x.

5. Morgan B. Rugby in South Africa. South Africa Info. 201 I . <http:// www.southafrica.info/about/sport/rugby.htm > (4 July 20I5).

6. Steinwender S and Leclair L. Occupation, Health and Wellbeing. Canadian Journal of Occupational Therapy, I998; 65(2): 8I-9I. https://doi.org/ I 0. I I 77/00084 I 749806500204.

7. Sohi AS and Singh K. A Study of Family's Role as a Social System in Socialization of Sportsmen into Sports in Nigeria. 1983. In: Mangan JA and Small RM (Eds.). Sport, Culture, Society: International, historical and sociological perspectives. Proceedings of the VIII commonwealth and international conference on Sport, Physical Education, Dance, Recreation and Health Conference '86 Glasgow 18-23 July. London: E \& F N Spon; 1986: 246-252.

8. Hatzigeorgiadis A, Morela E, Elbe A, Kouli O and Sanchez X. The Integrative Role of Sport in Multicultural Societies. European Psychologist. 2013; 18(3): 191-202.

https://doi.org/10.1027/1016-9040/a000155.

9. Österlind $M$ and Wright J. If sport's the solution then what's the problem? The social significance of sport in the moral governing of 'good' and 'healthy' citizens in Sweden, 1922-1998. Sport, Education and Society. 2014; 19(8): 973-990. https://doi.org/10.1080/13573322.2012.726217.

10. Wagnsson, S, Lindwall M and Gustafsson H. Participation in Organized Sport and Self-Esteem across Adolescence: The Mediating Role of Perceived Sport Competence. Journal of Sports and Exercise Psychology. 2014; 36(6): 584-594.

https://doi.org/10.II23/isep.2013/jsep.2013-0137.

II. Forsyth K and Kielhofner GW. The Model of Human Occupation. 
In: Duncan EAS (Ed.) Foundations for Practice in Occupational Therapy. London: Churchhill Livingstone Elsevier. 20 I I: 55.

12. American Occupational Therapy Association. Occupational Therapy Practice Framework: Domain and process (3rd ed.). American Journal of Occupational Therapy, 2014; 68(I): SI-S48.

13. Riordan CM. How to Juggle Multiple Roles. 2013. <http://blogs. hbr.org/20I3/I0/how-to-juggle-multiple-roles/ > (4 June 20I4).

14. Baum CM and Christiansen CH. Person-Environment-OccupationPerformance: An Occupation-Based Framework for Practice. In: Christiansen CH, Baum CM and Bass-Haugen J (Eds.). Occupational Therapy Performance, Participation, and Well-being. Thorofare: Slack Incorporate; 2005: 253.

15. Moyers P. Introduction to Occupation-Based Practice. In: Christiansen $\mathrm{CH}$, Baum CM and Bass-Haugen J. Occupational Therapy Performance, Participation, and Well-being. Thorofare: Slack Incorporated, 2005: 223-225.

16. Turpin M and Iwama MK. Using Occupational Therapy Models in Practice: A field guide. London: Elsevier Ltd; 20 I I: |42-143.

17. Cole MB. Groups and the OT Practice Framework - II, chap. 4. Group Dynamics in Occupational Therapy $\left(4^{\text {th }}\right.$ ed.) United States of America: SLACK Incorporated; 2012: I I3.

18. Mazurkiewicz M. Some observations about ritual in sport. Studies in Physical Culture and Tourism, 20 I ; I8(4): 317-320.

19. Živanović N, Randelović N and Savić Z. Superstitions and Rituals in Modern Sport. Activities in Physical Education \& Sport, 20I 2; 2(2): 220-221.

20. Gross JJ and Thompson RA. Emotion Regulation: Conceptual Foundations. In: Gross JJ (Ed.), Handbook of Emotion Regulation. New York: The Guilford Press; 2007: 3-24.

21. Sapolsky RM. Stress, Stress-Related Disease, and Emotion Regulation. In: Gross JJ (Ed.). Handbook of emotion regulation. New York: Guildford; 2007: 606-6I5.

22. Eisenberg N, Fabes RA, Guthrie IK and Reiser M. Dispositional emotionality and regulation: their role in predicting quality of social functioning. Journal of Personality and Social Psychology, 2000; 78(I): |36-157. http://dx.doi.org/10.1037/0022-35|4.78.I.I36.

23. Murray SL. Regulating the risks of closeness: A relationship specific sense of felt security. Current Directions in Psychological Science, 2005; 14(2): 74-78. https://doi.org//0.1 I I I/j.0963-72|4.2005.00338.x.

24. Diefendorff JM, Hall RJ, Lord RG and Strean ML. Action-state orientation: Construct validity of a revised measure and its relationship to work-related variables. Journal of Applied Psychology, 2000; 85(2): 250-263. http://dx.doi.org//0.1037/002I-9010.85.2.250.

25. Lane AM, Beedie CJ, Jones MV, Uphill M and Davenport TJ. The bases expert statement on emotion regulation in sport. Journal of Sports Sciences, 201 I; 30(I I): I I89-1 I 95. https://doi.org//0.1080/026404I4.2012.69362I.

26. Lazarus RS and Folkman S. Stress, appraisal and coping. New York: Springer: 1984: 230-232.

27. Lane A. The BASES Expert Statement on Emotion Regulation in Sport. The Sport and Exercise Scientist, 20 I I; Autumn(29): I4-I5.

28. Reed KL. Appendix B. An Annotated History Of The Concepts Used in Occupational Therapy. In C.H. Christiansen, C.M. Baum, J. BassHaugen (Eds.), Occupational Therapy Performance, Participation, and Well-being. Thorofare: Slack Incorporated, 2005: 596.

29. Simmons JM. Fan-family conflict: An examination of inter-role conflict between sport fan and family roles. Dissertation Abstracts International Section A: Humanities and Social Sciences, 2012; 72(I2-A): 4456. https://doi.org// 0.18297/etd// 328.

30. Stubley T, Rojas M and McCroy C. Father's Perceptions about Their Fathering Role. Journal of Arts \& Humanities, 2015; 4(4): 73. http://dx.doi.org/10.18533/journal.v4i4.625.

31. Cinamon RG and Rich Y. Gender Differences in the Importance of Work and Family Roles: Implications for Work-Family Conflict. Sex roles, 2002; 47(II//2): 53I-54I. https://doi.org/10.1023/A:1022021804846.

32. McGregor L. Play Rugby, but plan another career: Salaries for the vast majority of professional players are low. 2015. At <www.rdm. co.za/sport/2015/04/09/play-rugby-but-plan-another-career $>$ (4 July 2015).

33. Rugby 15. It's All About Rugby! 2014. <http://www.rugbyl5. co.za/20l4/I0> (5 Nov 20l4).
34. Karageorghis $C$ and Terry P. Balance intrinsic and extrinsic motivation for success. Inside Sport Psychology. 20I 5. <www.humankinetics. com/excerpts/expcerts/balance-intrinsic-and-extrinsic-motivationfor-success $>$. (4 July 20I5).

35. Rugbyklub van die Universiteit van die Vrystaat, Konstitusie van die Rugbyklub van die Universiteit van die Vrystaat, Bloemfontein, South Africa, 2008: 5.

36. Christiansen $\mathrm{CH}$, Baum CM and Bass-Haugen J. Occupational Therapy Performance, Participation and Well-being. Thorofare: SLACK Incorporated, 2005: 223, 253, 527, 596.

37. American Occupational Therapy Association (AOTA). Occupational Therapy Practice Framework: Domain and Process. The American Journal of Occupational Therapy, 20I4; 68(I): S7-S8.

38. Clowes $\mathrm{H}$ and Knowles Z. Exploring the Effectiveness of PrePerformance Routines in Elite Artistic Gymnasts: A Mixed Method Investigation. Science of Gymnastics Journal, 20I3; 5(2): 27-40.

39. Laukka $P$ and Quick L. Emotional and motivational uses of music in sports and exercise: A questionnaire study among athletes. 2013; <http://web.b.ebscohost.com/ehost/detail/ detail?vid $=6 \&$ sid $=c c 2 c a 3 a 6-f 69 c-4 b b 9-95 c 6-428485 \mathrm{dcc} 7 \mathrm{aa} \% 40$ sessionmgr | | 3\&hid $=$ I | 8\&bdata $=$ JnNpdGU9ZWhvc3QtbGA2Z $Q \% 3 d \% 3 d \# d b=p s y h \& A N=20 \mid 3-10964-003>$. (4 July 20I5).

40. Jarraya M, Chtourou H, Aloui A, Hammouda O, Chamari K, Chaouachi $A$ and Souissi N. The Effects of Music on High-intensity Short-term Exercise in Well Trained Athletes. Asian Journal of Sports Medicine, 20I2; 4: 233-238.

4I. Brown C. Motivation. In Stoffel V, Brown C (Eds.), Occupational Therapy in Mental Health: A Vision for Participation, Philadelphia: FA Davis Co. 201 I; 330-344.

42. Hall CR, Rodgers WM and Barr KA. The Use of Imagery by Athletes in Selected Sports. The Sport Psychologist, 1990; 4:1-10. http://doi.org/10.1 I23/tsp.4.I.I.

43. Coetzee FF. (coetzeef@ufs.ac.za) Rugby. 20I5, Email to: Human, J. (ninih93\#gmail.com). (4 July 20I5).

44. Nicholls AR, Holt NL, Polman RCJ and Bloomfield J. Stressors, coping and coping effectiveness among professional Rugby Union players. The Sport Psychologist, 2006; 20(I): 314-329. https://doi.org/10.II 23/tsp.20.3.3 I4.

45. Collier G. Emotional Expression. New York: Psychology Press, 20I4: $\mathrm{I}-2$.

46. Maxwell JP, Moores EJ and Chow CFC. Anger rumination and self-reported aggression amongst British and Hong Kong Chinese athletes: A cross cultural comparison. International Journal of Sport and Exercise Psychology, 2007; 5(I), 9-27. https://doi.org/10.1080/1612197X.2008.967/8I0.

47. Robazza $C$ and Bortoli L. Perceived impact of anger and anxiety on sporting performance in rugby players. Psychology of Sport and Exercise, 2007; 8: 875-896. https://doi.org//0.1016/j.psychsport.2006.07.005.

48. Dubihlela J and Chinomona R. The prevalence of athlete hostility, anger, verbal and physical aggression within South African sport. African Journal for Physical, Health Education, Recreation and Dance, 2014; 20(I): 89-105.

49. Gross JJ. Emotion regulation: Affective, cognitive, and social consequences. Psychophysiology, 2002; 39(3): 28I-29I. https://doi.org//0.1017/S0048577201393198.

50. Gross JJ and John OP. Emotion Regulation Questionnaire ERQ. 2003. <http://www.fetzer.org/sites/default/files/images/stories/ pdf/selfmeasures/Self_Measures_for_Personal_Growth_and_Positive Emotions EMOTION REGULATION.pdf $>$. (2 September $201 \overline{4})$.

5I. Abler B, Erk S, Herwig $U$ and Walter $\mathrm{H}$. Anticipation of aversive stimuli activated extended amygdale in unipolar depression. Journal of Psychiatric Research, 2007; 4I (6): 5I I-522. https://doi.org/I0.1016/j.jpsychires.2006.07.020.

Corresponding Author

Petronella Hough

Email: HoughPA@ufs.ac.za 